\title{
Spatial division of labour of Schoenoplectus americanus
}

\author{
Makihiko Ikegami · Sander van Hal • \\ Jan W. A. van Rheenen · Dennis F. Whigham • \\ Marinus J. A. Werger
}

Received: 3 November 2006/Accepted: 15 February 2008/Published online: 7 March 2008

(C) The Author(s) 2008

\begin{abstract}
If connected ramets are growing in heterogeneous environments, Division of Labour (DoL) among ramets potentially will result in more efficient sharing of resources and an overall benefit to the plants. As a result of DoL, connected ramets growing in a heterogeneous environment might achieve more biomass than ramets growing in a homogeneous environment. DoL has been demonstrated to occur in a few clonal plant species, although most studies simply focussed on biomass allocation, not on actual resource capturing such as water and nutrient consumption. The model system for our study is one in which two connected ramet groups of Schoenoplectus americanus were placed into contrasting environments. In one treatment, the connected ramets grew in heterogeneous environments and in the other treatment, the connected ramets grew in the same (i.e. homogeneous) environment. We manipulated two
\end{abstract}

M. Ikegami · S. van Hal · J. W. A. van Rheenen ·

M. J. A. Werger

Department of Plant Ecology \& Biodiversity,

Utrecht University, P.O. Box 80084, 3508 TB Utrecht,

The Netherlands

M. Ikegami · D. F. Whigham

SERC, P.O. Box 28, 647 Contees Wharf Road,

Edgewater, MD 21037, USA

\section{Ikegami ( $($ )}

Forest Research, Alice Holt Lodge, Wrecclesham,

Farnham, Surrey GU10 4LH, UK

e-mail: makihiko@mbox.kyoto-inet.or.jp variables (light and salinity) in the experiment. We hypothesized that ramets growing in a shaded and fresh water condition in a heterogeneous environment would use more water than ramets growing in a similar condition but in a homogeneous environment. We further hypothesized that ramets growing in a light and saline condition in a heterogeneous environment would assimilate less water than ramets growing in a similar condition but in a homogeneous environment. These hypotheses are based on the assumption that ramets in a heterogeneous environment would translocate water from ramets growing in a shaded and fresh water condition to ramets growing in a light and saline water condition. We also hypothesized that ramets growing in heterogeneous environments achieve larger biomass than ramets in homogeneous environments. Ramets grown in light and saline conditions in heterogeneous environments allocated more biomass to aboveground parts, had taller shoots, larger Specific Green (leaf) Area and consumed less water than ramets grown in similar conditions but in a homogeneous environment. Results confirm the hypothesis that connected ramets in heterogeneous environments are specialised to capture locally abundant resources and share these with connected ramets growing in other habitats. The result of DoL is that the entire connected ramet system benefits and achieves higher biomass.

Keywords Clonal plant - Division of labour . Heterogeneous environments .

Schoenoplectus americanus 


\section{Introduction}

Clonal plants spread horizontally by vegetative growth and thus have the potential to spread over an area that is likely to be environmentally heterogeneous. Clonal plants are also known to share resources among ramets growing in different environmental conditions which allows the genet to be buffered against external differences in resource supply (Marshall 1990; Hutchings and de Kroon 1994). The ability to share resources among ramets growing in different conditions thus allows clonal plants to perform well in patchy environments (Alpert and Mooney 1986; Wijesinghe and Handel 1994; Alpert 1995; Stuefer et al. 1996, 1998; Hutchings 1999).

In patchy and heterogeneous environments, resource availability is not uniformly distributed and different resources may be negatively correlated with each other in a spatial context (Young and Smith 1979, 1980; Schulze and Hall 1982; Schlesinger et al. 1990). In patchy environments some clonal plant species are known to show functional specialisation by capturing locally abundant resources and exchanging them among ramets through physiological integration (Stuefer et al. 1996; Alpert and Stuefer 1997). Accordingly, ramets growing in patches with high light but low water availability invest strongly in leaves instead of roots and the increased carbon assimilate is transported to ramets growing in lower light environments. In patches with low light but high water availability, on the other hand, ramets strongly invest in roots instead of leaves and the assimilated water is transported through physiological integration to ramets growing in patches where water resources are less available (Stuefer et al. 1996; Alpert and Stuefer 1997; Alpert 1999). Thus, in clonal plants, resources are captured where they are most abundant and then transported to places where those resources are in short supply. Physiological integration allows this functional specialisation of ramets, and as a consequence, the integrated clone performs significantly better in spatially heterogeneous than in homogeneous environments with the same total level of resources (Alpert and Stuefer 1997; Hutchings and Wijesinghe 1997). Stuefer et al. (1996) referred to this allocation pattern as spatial Division of Labour (hereafter referred to as DoL) in analogy to such a term in Economy. According to Stuefer et al. (1996),
DoL requires reciprocal resource translocation and functional specialisation of ramets to capture locally abundant resources.

DoL in clonal plants has only recently been documented and the generality of DoL among clonal plants and the ecological consequences of DoL have not been thoroughly studied. Stuefer et al. (1996) focussed on ramet biomass and the allocation of resources to the aboveground and belowground parts of ramets. van Kleunen and Stuefer (1999) examined patterns of biomass allocation in a species that demonstrated DoL and their research also considered variations in specific leaf area. Focussing studies on resource allocation to biomass only provides a partial understanding of resource allocation in species that have demonstrated DoL. A larger aboveground biomass does not, for example, necessarily mean that plants allocate more biomass to the lightcapturing organs, and a larger below ground biomass does not mean that plants capture more water. Some clonal plants allocate large amounts of belowground biomass to stem structures (see Ikegami et al. 2007a) which are not specialised for water uptake. In order to demonstrate that DoL results in a more efficient uptake of water it would also be important to measure water consumption as well as belowground biomass. Similarly, to demonstrate DoL in clonal species growing in heterogeneous environments, it would also be appropriate to measure the amount of resources allocated to light capturing units, such as Specific Leaf Area, as well as aboveground biomass.

Schoenoplectus americanus demonstrates highly variable patterns of growth in a wide range of brackish wetlands in the USA. Within the Rhode River sub-estuary of Chesapeake Bay S. americanus occurs in habitats with differing light and salinity regimes ranging from plants in full sunlight to plants that are shaded continuously or for part of the day by trees near the wetland-upland border (Ikegami et al. 2006). Salinity varies over relatively small spatial scales in response to variations in microtopography, patterns of tidal flooding, and input of freshwater from adjacent upland habitats (Bertness et al. 1992). As S. americanus grows in range of habitat types that are characterized by small-scale spatial differences in salinity and light, and one genet sometimes grows in different habitat patches, DoL may, in part, be responsible for the success of this species. 
In order to evaluate DoL in S. americanus, we conducted a garden experiment focussing on light availability and salinity (Fig. 1). We placed pairs of connected ramets in similar or dissimilar conditions. The two conditions used in the experiment were shade and fresh water (shaded-wet) or high light and saline water (light-salt). When both ramets of a pair were grown in a similar condition, the treatment was defined as "homogeneous" and when the two ramets of a pair were placed in different conditions, the treatment was defined as "heterogeneous".

We tested the following four hypotheses:

(1) Ramets grown in heterogeneous environments ( 1 and 2 in Fig. 1) would produce more total biomass than ramets grown in homogeneous environments (3 and 4 in Fig. 1).

(2) Ramets grown in the shaded-wet conditions in heterogeneous environments (SRG in condition (1) and PRG in condition (2) in Fig. 1) would

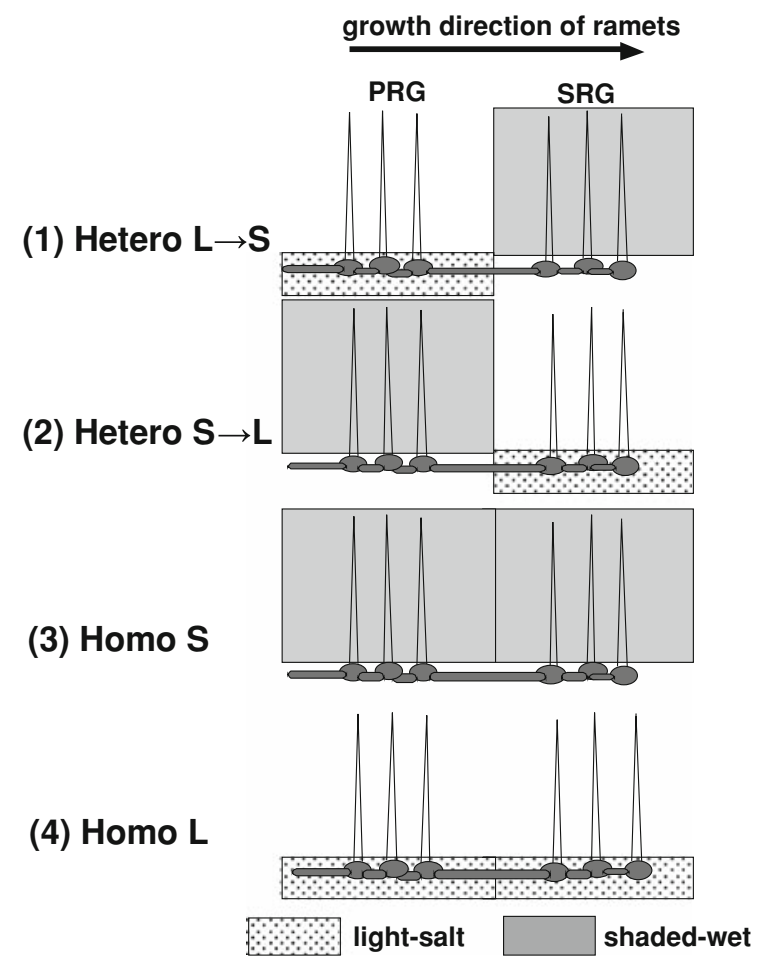

Fig. 1 Schematic representation of the four treatments. "Hetero L $\rightarrow \mathrm{S}$ " and "Hetero $\mathrm{S} \rightarrow \mathrm{L}$ " are heterogeneous treatments with a combination of shaded-wet and light-salt containers (1 and 2). "Homo S" and "Homo L" are homogeneous treatments with two shaded-wet containers (3) and light-salt containers (4). PRG, primary ramet group; SRG, secondary ramet group consume more water than ramets in the shadedwet conditions in the homogeneous environment (PRG and SRG in condition (3) in Fig. 1). Ramets grown in the light-salt conditions in heterogeneous environments (PRG in condition (1) and SRG in condition (2) in Fig. 1), on the other hand, would consume less water than ramets grown in similar conditions but in the homogeneous environment (PRG and SRG in condition (4) in Fig. 1).

(3) Ramets grown in the shaded-wet conditions in a homogeneous environment (PRG and SRG in condition (3) in Fig. 1) would have proportionally more aboveground biomass than ramets grown in similar conditions but in heterogeneous environments (SRG in condition (1) and PRG in condition (2) in Fig. 1). Ramets grown in the light-salt conditions in heterogeneous environments (PRG in condition (1) and SRG in condition (2) in Fig. 1), on the other hand, would have proportionally more aboveground biomass than ramets grown in similar conditions but in a homogeneous environment (PRG and SRG in condition (4) in Fig. 1).

(4) Ramets grown in shaded-wet conditions in a homogeneous environment (PRG and SRG in condition (3) in Fig. 1) would have taller shoots with greater Specific Leaf Area (hereafter referred to as SGA; Specific Green Area) than ramets grown in light-salt conditions in a homogeneous environment (PRG and SRG in condition (4) in Fig. 1) and ramets in shadedwet conditions in heterogeneous environments (PRG in condition (1) and SRG in condition (2) in Fig. 1).

\section{The experiment}

Test species

Schoenoplectus americanus (Pers.) Volk. ex Schinz \& R. Keller., is a common species in brackish wetlands in the Maryland portion of Chesapeake Bay where it occurs in habitats that range from low to high salinities (McCormick and Somes 1982; Drake 1984; Ikegami et al. 2006). The current species name is synonymous with Scirpus olneyi A. Gray, a name 
that is commonly seen in the wetlands literature. In the field, S. americanus demonstrates highly variable patterns of growth and genets appear to place ramets in more than one habitat simultaneously (D. F. Whigham, personal observation). Individual ramets consist of a shoot, roots and a tuber that produces one or more rhizomes that vary in length (Ikegami 2004; Ikegami et al. 2006, 2007a). Aboveground shoots are either vegetative or reproductive and they are erect, sharply triangular, needle-like, and green with rudimentary leaves. A below ground ramet consists of a tuber and rhizome; some tubers have measurable rhizomes while others, mainly on side branches, do not. Thus the lengths of below ground ramets are highly variable, ranging from about 0.7 to $20.0 \mathrm{~cm}$ in the field (Ikegami et al. 2006, 2007a).

\section{Methods}

In 1999, we collected plant material from three different brackish tidal wetlands at the Smithsonian Environmental Research Center (SERC), Edgewater, Maryland, USA. The plants were propagated clonally in the greenhouse at the Uithof Botanical Gardens at Utrecht University, The Netherlands. As the plants were collected over a wide area, from three wetlands at SERC, we believe that they were all of different genotypes.

In 2000, we chose healthy clonal fragments, each consisting of two separate groups of ramets that were connected by a long rhizome. Each group had one to three ramets. We scored the ramets in each group as being either Primary Ramets (PRG) or Secondary Ramets (SRG) based on their location relative to the terminal position of the rhizome system. SRG were the younger ramets produced by the older (PRG) ramets and both PRG and SRG had several buds that could produce new ramets (Fig. 1). Each pair of ramet groups was subjected to different light (two levels) and salinity (two levels) conditions; high light levels coincided with high salt levels and low light levels coincided with low salt levels (fresh water). Each ramet group was planted in two connected containers $(30 \mathrm{~cm} \times 15 \mathrm{~cm} \times 10 \mathrm{~cm})$ and the ramets remained connected (Fig. 1). Slots were cut in each container to accommodate the rhizome that connected the ramet in the two containers. Plastic putty was used to seal the containers around the rhizome to prevent the movement of water between containers.
Shading was imposed by placing shade cages, covered with shade cloth, over ramets. The cages transmitted $20 \%$ of ambient photosynthetic photon flux density (PPFD). Unshaded plants were exposed to ambient PPFD in the greenhouse (90\% of full sunlight). Salinity treatments were watering with $1 \%$ salt solution, using commercial table salt, and fresh water. In the heterogeneous light-salt to shaded-wet treatment (Hetero $\mathrm{L} \rightarrow \mathrm{S}$ in Fig. 1), the PRG members of each pair were placed in ambient light and $1 \%$ salt solution (light-salt container) while the SRG members of each pair were placed in shade with fresh water (shaded-wet container). The heterogeneous shaded-wet to light-salt treatment (Hetero $\mathrm{S} \rightarrow \mathrm{L}$ in Fig. 1) was the reverse of the Hetero $\mathrm{L} \rightarrow \mathrm{S}$ treatment (Fig. 1). We constructed these two heterogeneous treatments because we expected there could be differences in growth and resource translocation patterns between PRG and SRG. We used two control treatments in which both groups of ramets were placed in homogeneous environments; homogeneous shaded-wet treatment (Homo S in Fig. 1) and homogeneous light-salt treatment (Homo L in Fig. 1). The planting medium was a 3:1 mixture of peat and sand that received an N-based fertiliser $(25 \mathrm{~kg}-\mathrm{N} / \mathrm{ha}$ of OSMOCOTE) at the beginning of the experiment. Water levels and salinity were maintained at a constant level by regularly adding tap water. The volume of tap water added to each container was measured.

\section{Experiment}

The paired ramet groups were randomly assigned to each treatment and planted at the beginning of summer and salinity was gradually increased to $1 \%$ over a 2-week period. Shading treatments were added at the end of the 2-week period. Water consumption by ramets was calculated as the sum of the amount of water added to a container to maintain similar water levels in the containers. We harvested the experiment after 4 months. For each treatment, we first severed the shoots from the rhizomes keeping the material from each treatment combination separate. We then removed the belowground biomass from each container and washed the roots and rhizomes free of sediment. We randomly chose five shoots from each container and measured the length, the width of the broadest side of the triangular shoots at $10 \mathrm{~cm}$ above 
the soil surface, and the hypotenuse of the "triangle" at that point. We used the shoot data to calculate the Green Area (GA) per shoot, defined as the total surface area of the triangular pyramidal shoot. After $72 \mathrm{~h}$ of drying at $68^{\circ} \mathrm{C}$, we measured individual weights of five shoots, total shoot weight, rhizome weight and calculated the SGA per shoot, as the GA divided by the shoot weight. The numbers of replicates in treatments were 13 each at the beginning of the experiment but because of mortality of ramet groups, the samples size at the end of the experiment was $11,11,9$ and 10 for the Hetero $\mathrm{S} \rightarrow \mathrm{L}$, Hetero $\mathrm{L} \rightarrow \mathrm{S}$, Homo $\mathrm{S}$ and Homo L, respectively.

Data analysis

We used a square transformation for aboveground to total biomass ratio data, reciprocal transformation for water consumption data and logarithm transformation for water consumption per biomass data. One-way ANOVA was used to compare the mean number of ramets, the mean biomass of ramets, the ratio of aboveground to total biomass, shoot height, SGA, mean water consumption and mean water consumption per unit biomass among light-salt containers and among shaded-wet containers. We also used one-way ANOVA to compare mean of the total number or ramets, total biomass of ramets and total amount of water consumption among four treatments. TukeyKramer tests were used to compare the differences among containers or treatments. The $t$-test was used to compare differences between the SRG and PRG per treatment. All statistical analyses were made by using StatView Ver. 5.0 (SAS Institute 1998).

\section{Results}

Production of ramets and biomass

The total number of ramets did not differ significantly among treatments even though there were more ramets at the end of the experiment in the heterogeneous treatments (Fig. 2a). Total biomass was also higher in the heterogeneous treatments (Fig. 2b), but the difference was only statistically significant between the Hetero $\mathrm{L} \rightarrow \mathrm{S}$ and Homo L treatments (Fig. 2b). The SRG had more shoots and greater biomass in the heterogeneous treatments (Hetero (a) number of ramets

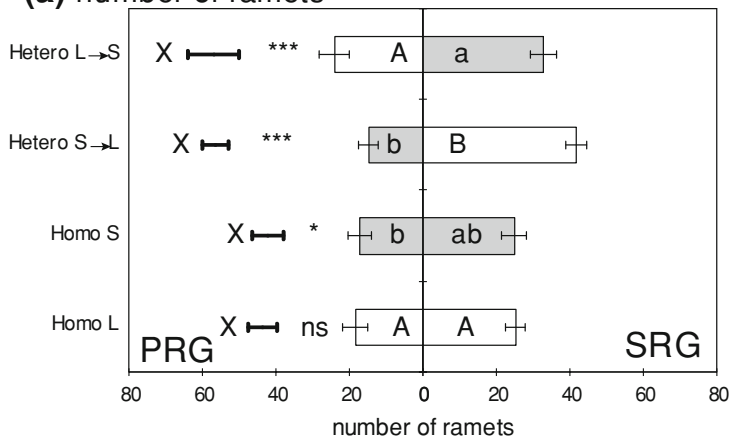

(b) biomass of ramets

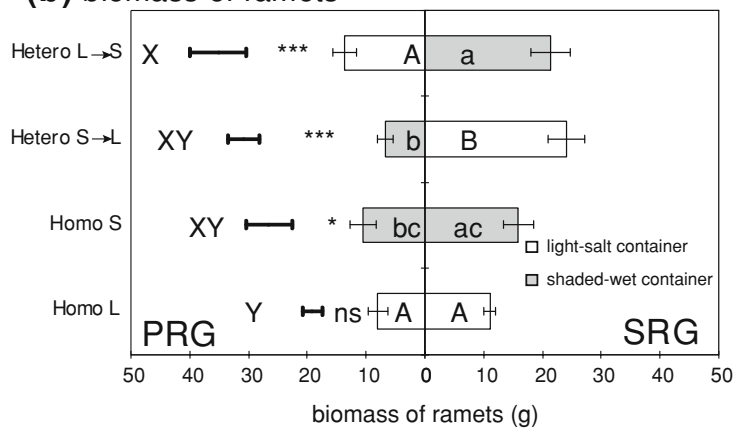

Fig. 2 Number and biomass of ramets produced by Schoenoplectus americanus in the four treatments (treatments as in Fig. 1). Open and shaded bars give mean values with standard errors of the number (a) and biomass (b) of ramets, grown in the light-salt containers (open bar) and shaded-wet containers (shaded bar). The bars for primary ramet group (PRG) are on the left side and for secondary ramet group (SRG) on the right. Independent error bars on the left are mean values with standard errors of total number (a) and total biomass (b) of ramets. Different letters indicate statistically significant differences among treatments with the Tukey-Kramer test. Lower cases $(a, b$ or $c)$ inside bars indicate differences among the ramets grown in the shaded-wet containers, capitals (A or B) among the light-salt containers and capitals on the left end of the independent bars ( $\mathrm{X}$ or $\mathrm{Y}$ ) indicate differences among four treatments. Asterisks on the left side of the bars indicate statistical significance between the PRG and SRG with the $t$-test. $* P<0.05 ; * * * P<0.001$; ns, not significant

$\mathrm{L} \rightarrow \mathrm{S}$ and Hetero $\mathrm{S} \rightarrow \mathrm{L}$ ) compared to the homogeneous treatments (Fig. 2a, b, also see Fig. 3).

Aboveground biomass ratio

In homogeneous environments, ramets allocated more biomass to the belowground parts in the light-salt containers, while ramets allocated more biomass to the aboveground parts in the shaded-wet containers 


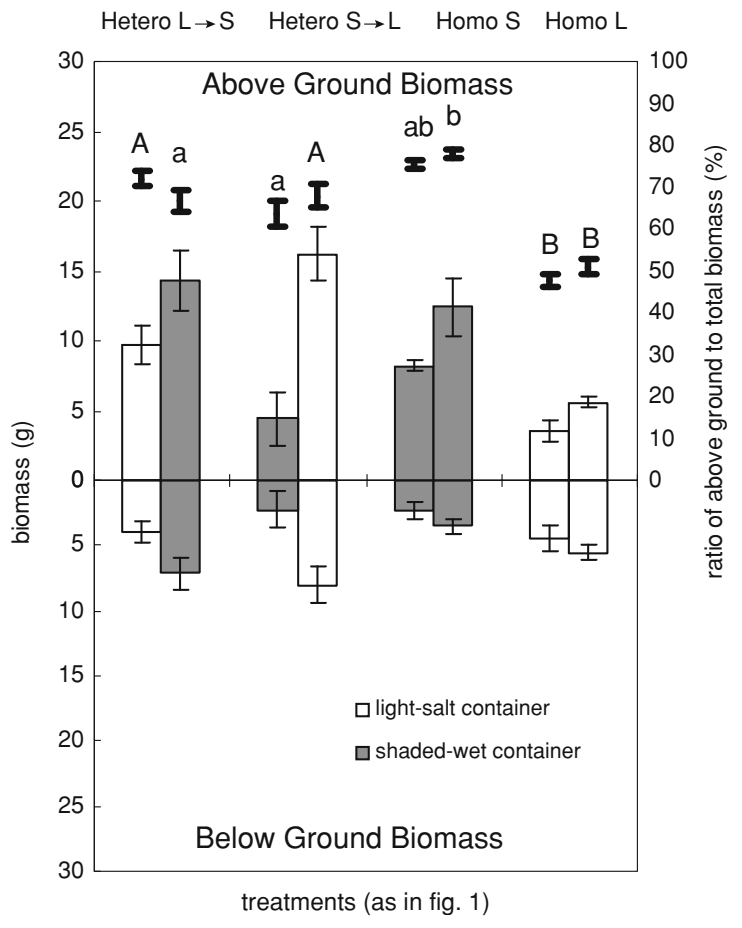

Fig. 3 Biomass allocation within ramet groups in the four treatments (treatments as in Fig. 1). Open and shaded bars (left axis) give mean values with standard errors of aboveground biomass (upper part of the graph) and belowground biomass (lower part of the graph) of the ramets grown in light-salt containers (open bar) and shaded-wet containers (shaded bar). In a pair of two bars, a left bar gives a value for the primary ramet group and a right bar for the secondary ramet group. Independent error bars (right axis) give the mean ratio of aboveground biomass to total biomass with standard errors. Different letters above bars indicate statistically significant differences among ramets grown in the light-salt containers in capitals and shaded-wet containers in lower cases with the Tukey-Kramer test

(Fig. 3). Ramets in heterogeneous environments had intermediate values for all variables. Ramets grown in the light-salt containers in heterogeneous environments allocated more biomass to aboveground parts than ramets in light-salt containers in the homogeneous environment, and ramets in shaded-wet containers in heterogeneous environments allocated more biomass to belowground parts than ramets in shaded-wet containers in the homogeneous environments (Fig. 3).

\section{Shoot shape}

Shoot height and SGA showed clear differences among treatments (Fig. 4). Shoots in the wet-shaded containers in the homogeneous environment (Homo S) were the tallest and had the largest SGA. Shoots in the light-salt containers in the homogeneous environment (Homo L) were the shortest and had the smallest SGA (Fig. 4a, b). Shoots in two heterogeneous environments (Hetero $\mathrm{L} \rightarrow \mathrm{S}$ and Hetero $\mathrm{S} \rightarrow \mathrm{L}$ ) had intermediate values. Ramets in the light-salt containers in heterogeneous environments had taller shoots with larger SGA values than ramets in the light-salt containers in the homogeneous environment (Fig. 4a, b). In the shaded-wet containers, ramets in heterogeneous environments had shorter shoots and smaller SGA values than ramets in the shaded-wet containers in the homogeneous environment (Fig. 4a, b).

\section{Water consumption}

In general, ramets in the shaded-wet containers consumed more water than ramets in light-salt containers. Among ramets growing in the shadedwet containers, PRG in the homogeneous environment consumed the least amount of water (Fig. 5a) while there were no differences among ramets in the light-salt containers (Fig. 5a). Among ramets growing in the light-salt containers water consumption per unit biomass by ramets in heterogeneous environments (Hetero $\mathrm{L} \rightarrow \mathrm{S}$ and Hetero $\mathrm{S} \rightarrow \mathrm{L}$ ) was less than in ramets in a homogeneous environment (Homo L) but it was not statistically significant between SRG in the Homo $\mathrm{L}$ treatment and PRG in the Hetero $\mathrm{L} \rightarrow \mathrm{S}$ treatment (Fig. 5b). Among the ramets in the shadedwet containers, water consumption per unit biomass was largest in PRG in the Hetero $\mathrm{L} \rightarrow \mathrm{S}$ treatment and smallest in SRG in the Hetero $\mathrm{S} \rightarrow \mathrm{L}$ treatment (Fig. 5b).

\section{Discussion}

Ramets in the shaded-wet containers in the homogeneous environment allocated proportionally more biomass to aboveground shoots than ramets in the light-salt containers in the homogeneous environment (Fig. 3). This response occurred because ramets compensated for resources that were locally limiting (i.e. light) and allocated more biomass to the organ that had to capture the most limiting resource (Aung 1974; Chapin 1980; Iwasa and Roughgarden 1984). 
(a)

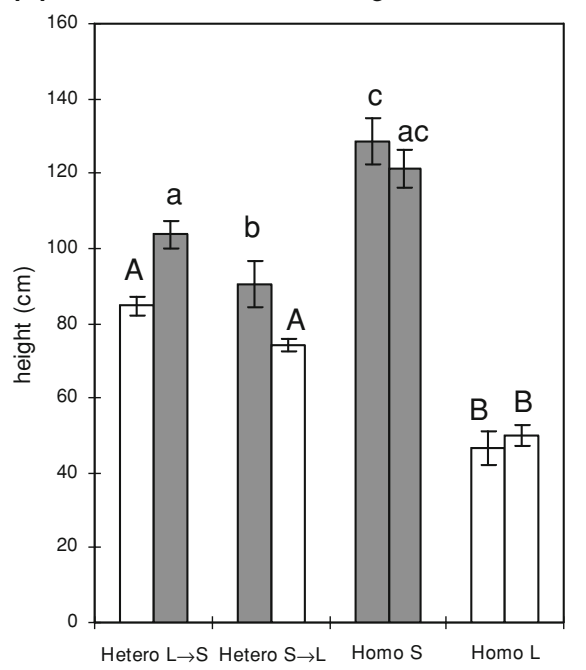

(b)

SGA

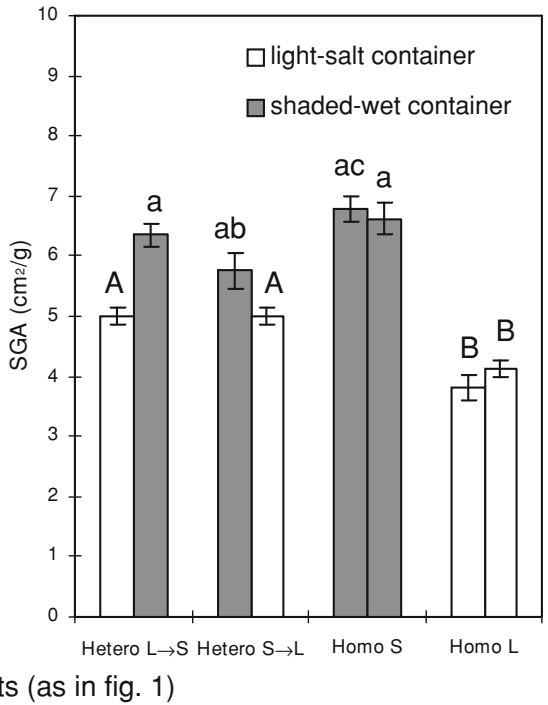

Fig. 4 Mean values of shoot height and specific green area (SGA) (treatments as in Fig. 1). Open and shaded bars give mean values with standard errors for shoot height (a) and SGA (b) of ramets grown in light-salt containers (open bar) and shaded-wet containers (shaded bar). In a pair of two bars, a left

Schoenoplectus americanus also showed functional specialisation in shoots as shoot height and SGA were greatest in ramets in the shaded-wet containers and lowest in ramets in the light-salt containers in homogeneous environments (Fig. 4). Tall shoots with a high SGA in the shaded-wet containers indicates that the shoots were capable of intercepting a greater amount of light per unit biomass, resulting in increased photosynthetic assimilation and net growth in shaded environments (i.e. etiolation). These results confirm that ramets specialised to improve the light capturing capacity in the shaded-wet containers in the homogeneous environment. In heterogeneous environments, ramets in the light-salt containers had proportionally more aboveground biomass (67 and $72 \%$ ) than the ramets in similar containers but in the homogeneous environment (48 and 51\%) and ramets in the shaded-wet containers had proportionally less aboveground biomass (63 and 66\%) than the ramets in similar containers but in the homogeneous environment (77 and 75\%; Fig. 3). Compared with ramets in homogeneous environments, ramets in heterogeneous environments had increased shoot height and SGA in the light-salt containers and lower values in the shaded-wet containers (Fig. 4). Thus, ramets bar gives a value for the primary ramet group and a right bar for the secondary ramet group. Different letters above bars indicate statistically significant differences among ramets grown in the light-salt containers in capitals and shaded-wet containers in lower cases with the Tukey-Kramer test

received more light per unit biomass in the lightsalt containers in heterogeneous environments than ramets in similar containers in the homogeneous environment. These results suggest that ramets grown in the light-salt containers in heterogeneous environments specialised in light capture instead of water capture. Although we did not measure photosynthesis, since the ramets in heterogeneous environments reached higher biomass values than the ramets in homogeneous environments, we conclude that S. americanus demonstrated spatial DoL in the sense of Stuefer et al. (1996).

In heterogeneous environments, the ratio of the aboveground biomass to the total biomass, shoot height and SGA of both light-salt and shaded-wet containers showed intermediate values compared to the two homogenous environments. Plants in the heterogeneous environments also did not differ between the light-salt and shaded-wet containers in heterogeneous environments (Figs. 3, 4a, b). Theoretically, the plants could have achieved greater biomass by allocating proportionally more biomass to the aboveground organs in the light-salt containers and to the belowground organs in the shaded-wet containers in heterogeneous environments; both 

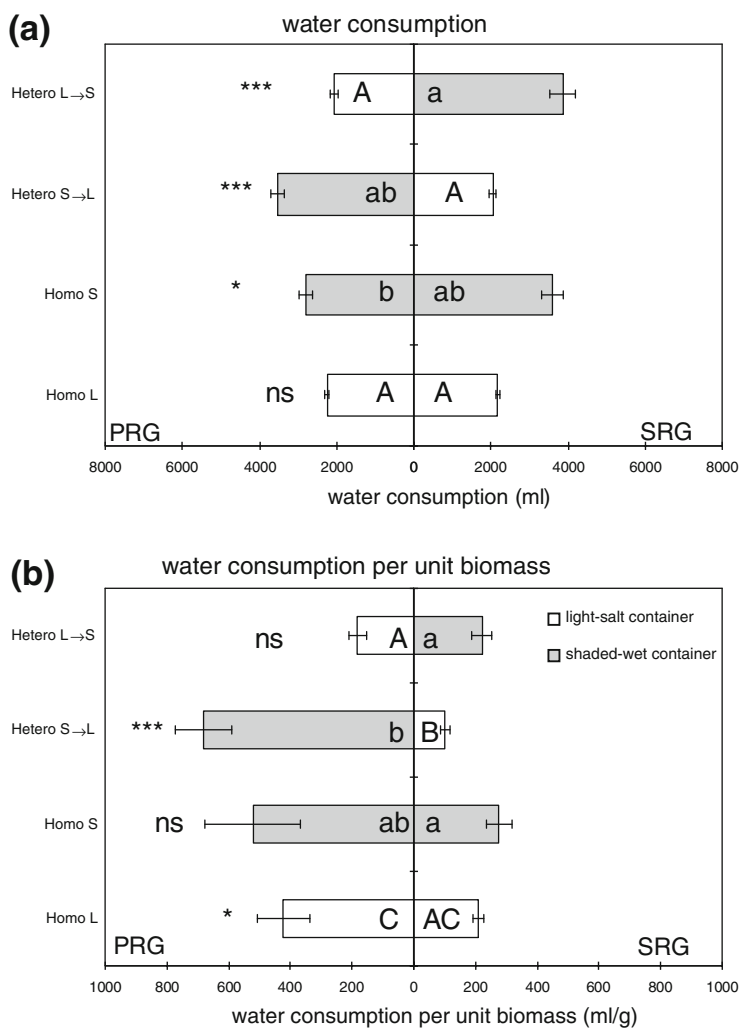

Fig. 5 Water consumption of ramets and water consumption per unit biomass in the four treatments (treatments as in Fig. 1). Open and shaded bars give mean values with standard errors for the ramets grown in the light-salt containers (open bar) and shaded-wet containers (shaded bar). The bars for the primary ramet group (PRG) are on the left side and for the secondary ramet group (SRG) on the right side. Letters inside bars indicate differences among ramets grown in the light-salt containers in capital and shaded-wet containers in lower case with the Tukey-Kramer test. Asterisks on the left side of the bars indicate statistical significance between the PRG and SRG with the $t$ test. $* P<0.05$; $* * * P<0.001$; ns, not significant

benefits of the ability to employ DoL. In a modelling study, Stuefer et al. (1998) suggested that plants that exhibit DoL do not always maximize the patterns of resource allocation in heterogeneous environments and thus avoid the consequences of the risk of severing the connection between ramets and isolating parts of the genet which have become specialised to local resource conditions and would not be capable of surviving without the benefits of being connected to other members of the genet. Magyar et al. (2007) developed a spatially explicit model to investigate the costs and benefits of plasticity of ramets and found that plants would specialise in a modest way to avoid the risk of specialisation under changing environments. Changes in environmental conditions would put highly specialised ramets in a disadvantageous situation (Magyar et al. 2007). Ikegami et al. (2007b) found similar results when they developed a model to examine optimum biomass allocation patterns in DoL. Ikegami et al. (2007b) found that if the cost of water transportation between ramets was intermediate, then plants showed DoL but the changes in biomass allocation were rather limited. They concluded that the limited response in biomass allocation was due to the cost of transportation and efficiency of assimilation of resource per unit biomass. If transportation costs are rather high, then a small organ growing under a poor-quality condition may capture more resources per unit biomass and provide more benefit to the genet than the translocation of resources from a larger organ growing under better conditions.

If DoL is operative, we expected that ramets growing in the light-salt containers in heterogeneous environments (i.e. Hetero $\mathrm{L} \rightarrow \mathrm{S}$ and Hetero $\mathrm{S} \rightarrow \mathrm{L}$ treatments), would obtain water from ramets in the shaded-wet containers, resulting in proportionally less biomass allocation to belowground parts in the light-salt containers in heterogeneous environments compared to the light-salt containers in the homogeneous environment (Homo L). Figure 3 shows that this expected outcome was observed. We also found that water consumption per unit biomass in the lightsalt containers in heterogeneous environments was less than water consumption per unit biomass in the light-salt containers in the homogeneous environment (Fig. 5). These results also support the conclusion that $S$. americanus benefited by DoL in heterogeneous environments (Fig. 5). The water consumption in this study was, however, the total amount of water added to each container, which is the sum of water lost by transpiration of plants and evaporation from the water surface. Thus, our estimates of total water consumption are greater than the actual amount of water loss by transpiration would have been. Another way to consider the relative differences in water consumption is to compare water loss on a unit biomass basis. In the homogeneous environments water consumption per unit biomass was higher in PRG compared to SRG (Fig. 5b) but the differences were not significant. This trend was also found in the Hetero $\mathrm{S} \rightarrow \mathrm{L}$ treatment but not in Hetero $\mathrm{L} \rightarrow \mathrm{S}$ treatment (Fig. 5b). These results suggest that water 
was more readily transported from the older PRG to the younger SRG. de Kroon et al. (1998) studied resource sharing in a Carex flacca and showed that water was transported from mother to daughter ramets in a homogeneous environment. In our Hetero $\mathrm{S} \rightarrow \mathrm{L}$ treatment the direction of water movement (i.e. PRG to SRG) was from the container where water was abundant and where older ramets were growing (i.e. PRG container) to the other container where water was limited and where younger ramets were growing (i.e. SRG container). These results suggest that the differences between water consumption and water consumption per unit biomass in this combination are much larger compared to all other combinations of water availability and ramet age (Fig. 5a, b). In contrast, the direction of water movement in the Hetero $\mathrm{L} \rightarrow \mathrm{S}$ condition would have been against the water availability gradient. Water would need to move from a container where water is abundant and young ramets were growing (i.e. SRG container) to the other container where water was limited and older ramets were growing (i.e. PRG container). The factors that would influence the direction of water movement in this combination would counterbalance each other (i.e. from high to low availability versus from old to young ramets) and would result in small differences in water consumption per unit biomass between two containers.

Stuefer et al. (1996) studied spatial DoL in Trifolium repens and showed clear differences in allocation pattern and biomass. In their study, plants grown in heterogeneous environments produced $67 \%$ more biomass and $72 \%$ more ramets than plants in homogeneous environments. In our study, plants in heterogeneous environments had, on average, $44 \%$ more biomass and $32 \%$ more offspring ramets than plants in homogeneous environments. The lower values for $\%$ biomass and number of ramets produced may indicate that the contrast in environmental conditions in our experiment was smaller than those employed by Stuefer et al. in their experiments (Stuefer et al. 1996). In our study, the ratio of aboveground to total biomass in the light-salt containers in the heterogeneous environments was much higher (on average $20 \%$, Fig. 3) than the ratio of belowground biomass to total biomass in the shaded-wet containers in heterogeneous environments (on average $11.5 \%$, Fig. 3). These results suggest that differences in water availability between light-salt and shaded-wet treatments could have been less than the differences in light availability. Another possible explanation is the degree of specialisation among species and/or genotypes. Alpert et al. (2003) suggested that higher potential of resources sharing could be selected for in highly heterogeneous habitats, and this has been confirmed by several studies (Alpert et al. 2003; Sergio et al. 2007). The genotypes we used in this study might have originated from less severely contrasting environmental conditions.

The reciprocal distribution of resources in space is a key factor of DoL (Alpert 1995; Stuefer et al. 1998). Some studies used the reciprocal distribution of light and nutrients (e.g. Alpert et al. 2003; Sergio et al. 2007) while others used light and water (e.g. Stuefer et al. 1996, 1998). Measuring nutrient assimilation in belowground parts of the plants would be difficult in experiments with the reciprocal distribution of light and nutrients. Sergio et al. (2007) measured chlorophyll content that clearly shows the adaptation for light capturing, but they only measured the biomass of belowground parts. Other studies which used reciprocal distribution of light and water did not measure water consumption (Stuefer et al. 1996; van Kleunen and Stuefer 1999). Although our estimate of water consumption was an overestimate because of the approach that we used to measure it, this study is the first example to demonstrate DoL specialisation in water consumption (i.e. belowground specialisation). As interstitial salinity and light can vary greatly over relatively short distances in brackish tidal wetlands, it would be advantageous for clonal species to employ DoL to maximize resource capture. While this greenhouse experiment demonstrated that the study species is capable of DoL, further field-based studies are needed to confirm the observed patterns under natural conditions.

In support of the findings of this study, a theoretical model (Ikegami et al. 2007b) of the same plant system showed that the allocation pattern between above and belowground biomass reacts more sensitively compared to total biomass and even if plants did not show an increase in biomass in heterogeneous environmental conditions, the allocation pattern could change drastically. Our experimental results showed that the ratio of aboveground to total biomass was clearly different among treatments while total biomass and number of ramets 
showed much weaker differences. These results confirm the theoretical findings of Ikegami et al. (2007b).

Acknowledgements This study was financially supported by a grant to MJAW from the Andrew W. Mellon Foundation through the Smithsonian Institution and by the Faculty of Biology at Utrecht University. We also thank two anonymous reviewers for their comments that have improved this manuscript.

Open Access This article is distributed under the terms of the Creative Commons Attribution Noncommercial License which permits any noncommercial use, distribution, and reproduction in any medium, provided the original author(s) and source are credited.

\section{References}

Alpert P (1995) Does clonal growth increase plant performance in natural communities? Abstract Bot 19:11-16

Alpert P (1999) Effects of clonal integration on plant plasticity in Fragaria chiloensis. Vegetatio 141:99-106

Alpert P, Mooney HA (1986) Resource sharing among ramets in the clonal herb, Fragaria chiloensis. Oecologia 70:227-233

Alpert P, Stuefer JF (1997) Division of labour in clonal plants. In: de Kroon H, van Groenendael J (eds) The ecology and evolution of clonal plants. Backhuys, Leiden, pp 137-154

Alpert P, Holzapfel C, Slominski C (2003) Differences in performance between genotypes of Fragaria chiloensis with different degrees of resource sharing. J Ecol 91: $27-35$

Aung HL (1974) Root-shoot relationships. In: Carson EW (ed) The plant root and its environment. University Press of Virginia, Charlottesville, pp 29-61

Bertness MD, Gough L, Shumway SW (1992) Salt tolerances and the distribution of fugitive salt marsh plants. Ecology 73:1842-1851

Chapin FS III (1980) The mineral nutrition of wild plants. Annu Rev Ecol Syst 11:233-260

de Kroon H, van der Zalm E, van Rheenen JWA et al (1998) The interaction between water and nitrogen translocation in a rhizomatous sedge (Carex flacca). Oecologia 116:3849

Drake BG (1984) Light response characteristics of net carbon dioxide exchange in brackish wetland plant communities. Oecologia 63:263-270

Hutchings MJ (1999) Clonal plants as cooperative systems: benefits in heterogeneous environments. Plant Species Biol 14:1-10

Hutchings MJ, de Kroon H (1994) Foraging in plants: the role of morphological plasticity in resource acquisition. Adv Ecol Res 25:159-238

Hutchings MJ, Wijesinghe DK (1997) Patchy habitats, division of labour and growth dividends in clonal plants. Trends Ecol Evol 12:390-394
Ikegami M (2004) Functional specialization of ramets in a clonal plant network. PhD thesis, Utrecht University, Utrecht

Ikegami M, Whigham DF, Werger MJA (2006) Scirpus olneyi A. Gray shows phenotypical differentiation in a salt marsh of the east coast of the U.S.A. Pol Bot Stud 22:241-249

Ikegami M, Whigham DF, Werger MJA (2007a) Response of rhizome length and ramet production to resource availability in the clonal sedge Scirpus olneyi A. Gray. Plant Ecol 189:247-259

Ikegami M, Whigham DF, Werger MJA (2007b) Optimal biomass allocation in heterogeneous environments in a clonal plant-Spatial division of labor. Ecol Model (in press). doi:10.1016/j.ecolmodel.2007.11.016

Iwasa Y, Roughgarden J (1984) Shoot-root balance of plants: optimal growth of a system with many vegetative organs. Theor Popul Biol 25:78-105

Magyar G, Kun Á, Oborny B, Stuefer JF (2007) The importance of plasticity and decision-making strategies for plant resource acquisition in spatio-temporally variable environments. New Phytol 174:182-193

Marshall C (1990) Source-sink relations of interconnected ramets. In: van Groenendael J, de Kroon H (eds) Clonal growth in plant: regulation and function. SPB Academic, The Hague, pp 23-41

McCormick J, Somes HAJ (1982) The coastal wetlands of Maryland. Maryland Department of Natural Resources, Baltimore

SAS Institute (1998) Statview reference. SAS Institute, Cary, $\mathrm{NC}$

Schlesinger WH, Reynolds JF, Cunningham GL et al (1990) Biological feedbacks in global desertification. Science 247:1043-1048

Schulze ED, Hall AE (1982) Stomatal responses, water loss, and $\mathrm{CO} 2$ assimilation rates of plants in contrasting environments. In: Lange OL, Nobel PS, Osmond CB et al (eds) Encyclopedia of plant physiology, new series, vol 12B. Springer-Verlag, Berlin, pp 181-230

Sergio RR, Alpert P, Tharayil N et al (2007) Greater capacity for division of labour in clones of Fragaria chiloensis from patchier habitats. J Ecol 95:397-405

Stuefer JF, de Kroon H, During HJ (1996) Exploitation of environmental heterogeneity by spatial division of labour in a clonal plant. Funct Ecol 10:328-334

Stuefer JF, During HJ, Schieving F (1998) A model on optimal root-shoot allocation and water transport in clonal plants. Ecol Modell 111:171-186

Wijesinghe DK, Handel SN (1994) Advantages of clonal growth in heterogeneous habitats: an experiment with Potentilla simplex. J Ecol 82:495-502

van Kleunen M, Stuefer JF (1999) Quantifying the effects of reciprocal assimilate and water translocation in a clonal plant by the use of steam-girdling. Oikos 85:135-145

Young DR, Smith WK (1979) Influence of sunflecks on the temperature and water relations of two subalpine understory congeners. Oecologia 43:195-205

Young DR, Smith WK (1980) Influence of sunlight on photosynthesis, water relations, and leaf structure in the understory species Arnica cordifolia. Ecology 61:13801390 